\title{
The Relationship between Job Satisfaction and Turnover Intentions among Graduate Teachers a Case Study of Graduate Teachers in Koforidua, Ghana
}

\author{
Article by Abomah, Peter Worlanyo \\ Lecturer in Psychology Department of Psychology Methodist University College, Ghana \\ Email:abworlanyo@yahoo.com
}

\begin{abstract}
The reason why graduate teachers decide to quite their job is difficult to tell because of the complexity of turnover decision processes involving a large number of variables. This study therefore, aims at assessing how relative weights of teacher's satisfaction with salary, working conditions, and professional training experiences on job satisfaction affects turnover intentions, and actual turnover. One hundred graduate teachers made up of fifty males and fifty females were purposively sampled for the study. Data was gathered by administering a questionnaire which consists of three standardized scales, job satisfaction, turnover intentions, and perception of work environment. These scales elicited information on job satisfaction and turnover intention of the selected participants in addition to demographic data which elicited information on age, marital status, number of years in teaching among others. Findings revealed that work environment had no influence on job satisfaction and turnover intentions whiles job satisfaction correlates negatively with turnover intentions. Male participants expressed higher turnover intention than their female counterparts. It was also found that, number of years of service (tenure) has minimal influence on teachers' intentions to leave. It was concluded that in order to reduce turnover intentions among graduate teachers in order to resolve constant shortage of graduate teaching personnel, a lot more is needed to be done on job satisfaction among teachers.
\end{abstract}

\section{Introduction}

A number of models have been developed and tested to explain teachers' turnover behavior. The theories considered for the purpose of this research is the human capital theory and

Herzberg's (1968) dual-factor job satisfaction theory. The Human Capital Theory of occupational choice provides a conceptual framework for an understanding of some underlying factors that may contribute to an individual's decision to become a teacher, and subsequently, to remain in or leave teaching. (Becker, 1993; Ehrenberg \& Smith, 2003). It considers factors like monetary benefit, non-monetary benefits and professional training benefits. Herzberg's (1968) dual-factor job satisfaction theory suggests that there are two dimensions of job satisfaction: motivation and hygiene factors. Human capital theory provides a useful framework for understanding some underlying factors that may contribute to an individual's decision to become a teacher, and subsequently, to remain in or leave teaching. Generally speaking, human capital theory identifies a turnover decision on the basis of the real or perceived value of the job in relation to the investment an individual has made to become a teacher (Becker, 1993; Ehrenberg $\&$ Smith, 2003). One of the major principles of human capital theory is that the greater the amount of knowledge and skills accumulated in a job over time from investments in education and job training, the lower one's probability of turnover from that occupation (Ehrenberg \& Smith, 2003; Kirby \& Grissmer, 1993). Focusing on the costs and benefits, if the present value of the benefits associated with turnover exceeds the costs, people will make a decision to change. In other words, teachers who foregone rewards (i. e., opportunity costs of teaching)outweigh the rewards gained from teaching will be more likely to leave the teaching profession. This theory 
basically illustrates the relationships among education and training, migration and the search for a new job in terms of investment and its returns (Becker, 1993; Ehrenberg \& Smith, 2003). Expected utilities from turnover decisions are influenced by entry requirements (e. g., licensure), and future benefits such as better salary (monetary rewards), working conditions (non-pecuniary attribute), and professional training benefits. If the present value of the benefits associated with turnover exceeds the costs, individuals are more likely to make a decision to change jobs.

\section{Monetary benefits}

From the perspective of Human Capital Theory, monetary benefits (e. g., health/life insurance, pensions)from the teaching profession can be viewed as returns on investment in education and training. Such training may make individuals more productive, resulting in higher wages and the trade-offs associated with the costs (Becker, 1993). Generally speaking, if teachers feel that their return is being lowered as they work, they will be less likely to invest in training and thus leave. In other words, teachers who have perceived that they have put too much into teaching but have not gotten enough in return decide to leave (Becker, 1993).

\section{Non-monetary benefits}

Along with monetary benefits, teachers consider non-monetary benefits as one of the most important factors affecting their career decisions. In general, non-monetary benefits may include support from fellow teachers and administrators, the quality of school facilities and resources available, autonomy in classroom, participation in school decision-making, student learning attitudes, and assigned teaching hours generally considered as working conditions (Barro, 1992; Ingersoll, 2001 ). Scholars differentiate between firm-specific and generic human capital. Firmspecific human capital refers to factors that cannot be transferred to other schools, while generic human capital is that which can be easily transferred to other schools and professions. Firm specific human capital includes knowledge of school practices, seniority in the system, respect of colleagues, and other forms of autonomy and privilege (Becker, 1993; Black, 1997; Grissmer \& Kirby, 1987). In principle, the more firm-specific human capital that is built up, the less likely an individual is to leave that profession if the human capital is rewarded (Kirby \& Grissmer, 1993). Most researchers generally agree that working conditions and/or school level characteristics contribute significantly to teachers' decisions about where to work, along with monetary benefits (Ingersoll, 2001 ; Mont \& Rees, 1996; Theo bald \& Gritz, 1996). Compared to monetary benefits, working conditions have received less attention in earner literature (Barro, 1992; Ingersoll, 2001 ) .

\section{Professional training benefits}

Individuals increase their store of human capital through formal schooling and on-the job training which includes induction/mentoring programs and professional development programs. Training as investment in human capital can be labeled as general or specific. General training that accumulates generic human capital can be defined as any training that can be easily transferred to other professions and can increase an individual's future wages or benefits (Kirby \& Grissmer, 1993). In contrast, specific training that builds up firm-specific human capital can be defined as training which is specific to the school in which a teacher teaches or another school in the district (Kirby \& Grissmer, 1993). Human capital theory conceptualizes decisions individuals make to stay in or leave teaching as rational and based on the real or perceived value of the job versus the investment made to become a teacher. 


\section{Dual-factor job satisfaction theory}

Various theorists have proposed models that map out the various sources of satisfaction and dissatisfaction for job satisfaction in general and for teacher satisfaction in particular. The essential underlying conceptual difficulty associated with researching job satisfaction is that there is no agreed upon definition of the term. Often cited in education literature, Herzberg's (1968)Dual-Factor Job satisfaction theory suggests that there are two dimensions of job satisfaction: motivation and hygiene. The motivator or intrinsic rewards includes recognition, achievement, possibility of growth, advancement, responsibility, and work itself (Hirsch, 2001). Motivator factors cause positive job attitudes because they satisfy the worker's need for selfactualization, an individual's ultimate goal (Judge, Bono, \& Locke, 2000). Many enter teaching because they want to make a difference with children by successfully meeting their academic needs (Farkas, Johnson, \& Foleno, 2000). Therefore, teachers are satisfied according to this view, when they can facilitate learning and cultivate positive relationships with students. The hygiene or extrinsic dimension is similar to that explained by human capital theory. This dimension includes salary, supervision, administrative policies, working conditions, and interpersonal relations (Herzberg, 1968).

\section{Statement of the problem}

Some schools in Ghana were facing a critical demand for new teachers at the turn of the century (Ghana National Education Campaign Coalition, 2006). Many researchers and educators have identified the key source of this challenge as the high rate of teacher turnover. However, it appeared there was no consensus in the literature around the factors that affected teachers' turnover decisions, and furthermore, what factors were more or less important to those decisions. It is important for policy makers and educators to understand the relationships among job satisfaction, intent to leave, and actual turnover. This will provide a better understanding of the complicated turnover process and allow for more accurate prediction of whether dissatisfied teachers or teachers with high level of turnover intention actually left teaching. There are two major universities that are mandated to train graduate teachers in Ghana; University of Education Winneba and University of Cape Coast. Students from other universities are also recruited in the teaching service. Apart from that there are thirty-eight teacher training colleges that train teachers. There are also few private training colleges in Ghana. Despite the large turnout in the universities mandated to train graduate teacher, there is still the issue of high turnover leading to high teacher student ratio (in excess of the standard ratio of 1: 15). For instance for the 2008/9 academic year, the University of Cape Coast turned out 3, 766 although not all the graduates were teachers whilst 3, 153 graduated from the

University of Education. Currently, it is estimated that Ghana needed 24, 000 more teachers to augment its teaching capacity (Ghana National Education Campaign Coalition, 2006). Yet teachers are always not enough for the schools in the country. The question therefore is "What are the variables that contribute to teachers' satisfaction or dissatisfaction?"and indeed "what informs the decision of teachers to leave the noble profession? It is against this background and observation that this research was undertaking to find out how job satisfaction can be maximized to increase retention of graduate teachers in the development of teaching and learning in Ghana.

\section{Statement of hypothesis}

The following hypotheses were tested;

- Working environment will have a positive impact on teacher's job satisfaction.

- Job satisfaction will have a significant negative correlation on turnover intentions

- Working environment will have an inverse relationship with turnover intention.

- Males will have significantly high turnover intentions than females. 
South American Journal of Academic Research

Special Edition May 2016

- Teachers who have been in the teaching profession for less than 5 years will have higher intentions of leaving the teaching profession than those who have spent 5 yrs and above.

\section{Methodology}

\section{Research design}

An institutional case study was used in this study to investigate the relationship between job satisfaction and turnover intentions among graduate teachers in both public and private Senior High schools in Koforidua.

\section{Sampling size and sampling technique}

A sample of 100 teachers, 50 males and 50 females were selected for the study. Stratified random sampling technique was used since each gender constituted a stratum whereby respondents were chosen from. Out of the 100 respondents, 60 were married, ( 30 were males and 30 were females). Those who were single were 36 , (20 males and 16 females). Those who were widowed were only 2 and these were only females. Those who were divorced were also 2 and were only females. Out of the 100 respondents, 12 had been in the profession between 0 and 2 years $(12.0 \%), 30$ between 3 and 5 years $(30.0 \%), 12$ between 6 and 9 years $(12.0 \%), 12$ between 10 and 12 years $(12.0 \%$ )and 34 have been in the profession for 13 years and above (34. $0 \%$ ). Again out of the 100 respondents, 22 had served on a committee (22. $0 \%), 26$ on 2 committees $(26.0 \%), 14$ on 3 committees (14. $0 \%$ ), 4 on 4 committees (4. 0$), 5$ on 4 committees, 30 had not served on any committee. Out of the 100 teachers, 38 stayed close to their schools (38. 0\% )whiles 62 stayed far from their schools $(62.0 \%)$. Out of the 100, 52 participated in extra curricula activities (counseling "2", music "2", sports "38", housemistress "4", spiritual union "2", artist "2" studying "2")whiles 48 did not participate in any extra curricula activities. Out of the 100 respondents, 12 taught for at least an hour in a day (12.0\%), 24 for at least 2 hours $(24.0 \%), 22$ for at least 3 hours $(22.0 \%), 30$ for at least 4 hours $(30.0 \%), 12$ for at least 6 hours $(12.0 \%)$

\section{Material}

A 4-part standardized questionnaire was the main data collection instrument. Section A was on demographic data and this section elicited information on age, marital status, number of years of teaching among others.

Section B was an 18-item Job satisfaction scale developed by Brayfield and Rothe (1951 )with a reliability coefficient of 0.87 . This section tapped information on teachers' job satisfaction. Examples of the job satisfaction items were, "Is your job like a hobby", "Is your job usually interesting enough to keep you from getting bored?", "Are you enthusiastic about your job?" The reliability coefficient of job satisfaction for this sample was 0 . 8. It can then be explained that the scale to a higher extent tapped the information it purported to measure. In comparison with the original reliability coefficient $(0.87)$ it can be said that although there are differences it is not all that significant hence they are all reliable. It may be due to small sample size from this research. Section C was the 3-item turnover intention scale developed by O' Driscoli \& Beehr (1994)with an estimated Cronbach Alpha coefficient of 0. 91. This section tested teachers' intentions to quit. Sample questions included, "Do thoughts about quitting the job cross your mind?", "Do you plan to look for a new job within the next 12 months?", "How likely is it that over the next year, you will actively look for a new job outside?"

The Cronbach's alpha of turnover intention for this sample was 0.88 . This can be explained that the scale to a higher extent tapped the information it purported to measure. In comparison with the original Cronbach's alpha for the sample (0.91)it can be said that although there are differences it is not all that significant hence they are all reliable. This can be attributed to the 
small sample size in this research. Section 0 was a 20 -item scale measuring perception of work environment developed by Niehoff \& Moorman (1993). The Cronbach's alpha for the sample was 0 . 7. This section gathered information on teachers' perception of the working environment. Sample questions included; "Does your manager clarify decisions and provide additional information when requested?""Are job decisions applied consistently across all affected employees?"; "Are Employees allowed to challenge or appeal job decisions made by the manager?"The Cronbach's alpha of teachers' perception of work environment for this sample was 0.6. It can then be explained that the scale to a moderate extent tapped the information it purported to measure. In comparison with the original Cronbach's. alpha it can be said that there are differences and this can be attributed to the small sample size that participated in the current study.

\section{Procedure}

. An appointment was booked with prospective respondents; graduate teachers after permission were granted. The questionnaires were personally administered. To ensure availability of respondents at a time, questionnaires were administered when the school was on break during school hours. The questionnaires were collected two days after it had been administered.

\section{Scoring}

Responses on the job satisfaction questionnaire were scored on a 5-point Likert scale which ranged from: 'Strongly agree' for a score of 5, agree' for 4, undecided' for 3, disagree' for 2 and 'Strongly disagree' for 1 . Responses on the turnover intentions questionnaire were scored on a 6point response scale. Responses on the perception of work environment questionnaire was scored on a 5-point Likert type scale ranging from a 'very small extent' for a score of 1, to a 'small extent' for a score of 2, to 'a moderate extent 'for a score of 3, 'to a large extent' for a score of 4 and 'to a very large extent' for a score of 5 .

\section{Analysis}

The Pearson Product Moment correlation was used to analyze the first three hypotheses. The independent T-test was used in analyzing the fourth hypothesis. The researcher used the Statistical Package for Social Sciences (SPSS)version 11 for the data analysis. All the questionnaires were entered and the answers coded.

\section{Results}

\section{Working environment has a positive impact on teacher's job satisfaction.}

One of the hypotheses is that; working environment will have a positive impact on teacher's job satisfaction. Table 1 gives the Pearson Correlation Results on Teachers' Working Environment and Job satisfaction.

Table 1. Pearson' Correlation Results on Teachers' Working Environment and Job Satisfaction.

\begin{tabular}{|l|l|l|l|l|l|}
\hline Variables & Mean & Std. Deviation & df & obs & \\
\hline Working Environment & 62.26 & 12.21 & 98 & -006 & 0.48 \\
\cline { 1 - 5 } Job Satisfactory & 50.68 & 7.39 & & & \\
\hline
\end{tabular}

Sig. (1-tailed)

Table 1 shows that there is a negative correlation $[\mathrm{r}(98)=-0.006, \mathrm{p}=\mathrm{n}$. $\mathrm{s}]$ between working environment $[$ Mean $=62.26, \mathrm{SO}=12.21$ ] and job satisfaction $[\mathrm{Mean}=50.68, \mathrm{SO}=7.39]$. The hypothesis which states that; working environment will have a positive impact on teacher's job satisfaction is not supported by the data gathered. 
South American Journal of Academic Research

Special Edition May 2016

\section{Relationship between job satisfaction and teacher turnover intentions.}

The study was interested in knowing the extent to which teachers are satisfied with their job and the implication job satisfaction has on their intentions to continue or stop teaching. Table 2 below displays Pearson Correlation results on teachers' job satisfaction and turnover intentions.

Table 2. Pearson's Correlation Results on Teachers' Job Satisfaction and Turnover Intentions.

\begin{tabular}{|l|l|l|l|l|l|}
\hline Variables & Mean & Std. Deviation & Df & Robs & $p$ \\
\hline Job Satisfactory & 50.68 & 7.39 & 98 & -276 & 0.05 \\
\cline { 1 - 3 } Turnover intentions & 9.80 & 4.66 & & & \\
\hline
\end{tabular}

Sig. (1-tailed)

The results shows a negative correlation $[\mathrm{r}(98)=-0.276, \mathrm{p}<0.05]$ between job satisfaction $[\mathrm{Mean}=50.68, \mathrm{SD}=7.39]$ and turnover intention [Mean=9. 80, $\mathrm{SD}=4.66]$. The result supports the hypothesis which stated that "Job satisfaction will have a significantly negative correlation on turnover intentions".

\section{Relationship between working environment and turnover intentions}

Table 3. shows Pearson' Correlation Results on Teachers' Working Environment and turnover intentions.

\begin{tabular}{|l|l|l|l|l|l|}
\hline Variables & Mean & Std. Deviation & Df & Robs & $p$ \\
\hline Job Satisfactory & 62.26 & 12.21 & 98 & -.015 & 0.44 \\
\cline { 1 - 3 } Turnover intentions & 9.80 & 4.66 & & & \\
\hline
\end{tabular}

Sig. (1-tailed)

Table 3 reveals that there is an inverse relationship between $[\mathrm{r}(98)=-0.15, \mathrm{p}=\mathrm{n}$. s] working environment $[\mathrm{Mean}=62.26, \mathrm{SD}=12.21$ ] and turnover intentions [Mean=9. 80, $\mathrm{SD}=4$. 66]. The hypothesis which stated that there will be an inverse relationship between working environment and turnover intentions was not supported by the data gathered.

\section{Males will have significantly highly turnover intentions than females}

Table 4. Independent t- Test Results on Teacher Turnover Intention by Gender

\begin{tabular}{|l|ll|ll|l|l|l|}
\hline Variable & $\begin{array}{l}\text { Male } \\
\text { M }\end{array}$ & SD & M & SD & df & t obs & p \\
\hline $\begin{array}{l}\text { Turnover } \\
\text { Intention }\end{array}$ & 67.2451 & 0.3424 & 46.2641 & 2.2536 & 98 & 4.545 & 0.001 \\
\hline
\end{tabular}

To test for the difference in Turnover Intentions between male and female teachers, an independent $\mathrm{t}$-test was conducted on the data gathered. The results in table 4 show that male teachers $[M=67.2451, S D=0.3424]$ and female teachers $[M=46.2641, S D=2.2536]$ have significant difference in Turnover Intentions $[\mathrm{t}(98)=4.545, \mathrm{p}<0.05]$. Male teachers recorded a higher turnover intention mean score (67. 25)compare to that of female teachers (46. 26).

Meanwhile, the higher the mean, the greater the turnover intention. This means that the data gathered supports the hypothesis that males will have higher intention of leaving the teaching field than females. 


\section{Years in Teaching profession and intentions to quit}

The fifth hypothesis was that Teachers who have been in the teaching profession between 1 -

Table 5. Independent t- Test Results on Years in teaching profession and intentions to quit.

\begin{tabular}{|l|lr|ll|l|l|l|}
\hline & \multicolumn{2}{|l|}{ Between 1-5 yrs } & \multicolumn{2}{|l|}{ 5 yrs and above } & & & \\
in teaching & \multicolumn{2}{l|}{ in teaching } \\
Variable & M & SD & M SD & df & t obs & p \\
\hline $\begin{array}{l}\text { Turnover } \\
\text { Intention }\end{array}$ & 4.20 & 2.39 & 4.20 & 3.82 & 98 & 0.00 & 0.422 \\
\hline
\end{tabular}

$5 \mathrm{yrs}$ will have higher intentions of leaving the teaching profession than those who have spent 5 yrs and above.

In table 5 , at an alpha 0.05 , it is seen that the difference between teachers who have spent between 1-5 yrs $[\mathrm{M}=4.2, \mathrm{SD}=2.39]$ and Teachers who have spent $5 \mathrm{yrs}$ and above $[\mathrm{M}=4.2$, $\mathrm{SD}=3.82]$ is not significant $[\mathrm{t}((98)=0.00, \mathrm{p}=\mathrm{n}$. s]. The hypothesis which states that "Teachers who have been in the teaching profession between $1-5$ yrs will have higher intentions of leaving the teaching profession than those who have spent 5 yrs and above was not supported by the data gathered.

\section{Discussion}

\section{Working environment as a factor of job satisfaction.}

Locke and Lathan (1976)gave a comprehensive definition of job satisfaction as pleasurable or positive emotional state resulting from the appraisal of one's job or job experience. Locke and Lathan clarified that employees become satisfied if their working conditions; thus, autonomy, training and salary meet their personal demands. Comparative to this study, the data gathered on graduate teachers confirmed the hypothesis which stated that "there will be a negative relationship between working environment and job satisfaction". Practically, teachers see the satisfactory nature of their job from the kind of. teaching environment they find themselves in. This means that the more they perceive their working environment as not satisfactory the less they become satisfied. Job satisfaction has been defined in several ways but its materialization has always raised many questions. From the perspective of human capital theory, monetary benefits (e. g., health/life Insurance, pensions)from the teaching profession can be viewed as returns on investment in education and training. Such training intuitively makes individuals more productive, resulting in higher wages and the trade-offs associated with the costs (Becker, 1993). The analysis revealed that a greater number of the teachers $34 \%$ disagreed that they have satisfaction for the teaching job, as a reason, most of them $44 \%$ saw their working conditions to be very poor. According to the teachers, their working conditions do not truly reward them on the great impact they make on the society, specifically, the education given by them to students.

\section{The kind of relationship between job satisfaction and teacher turnover intentions.}

Dias-Serrano (2005)stated that Job satisfaction is considered a strong predictor of overall individual well being as well as a good predictor of intentions of decision of employees to leave a job. The issue of job satisfaction is of considerable importance to both employers and employees. The employer benefits from satisfied employees as they are more likely to profit from lower staff turnover intention which leads to actual turnovers. In the analysis from this study, it is established that there is a significantly negative relationship between job satisfaction and turnover intentions, explaining that if employees are not satisfied with their jobs they will be tempted to leave. On the contrary, they will stay if they are satisfied with their job. The implication is that graduate 
teachers saw their superiors to be unfair; they saw the Education Service as a weak body to create advocacy platform for teachers. According to Alexander (1998), turnover intentions are a direct predictor of real turnover and have a negative effect on job performance and productivity. Today, few people would disagree that the teacher is the most influential school related factor affecting the quality of education a student receives (Darling- Hammond, 1999; Sanders \& Rivers, 1996). Some researchers argue that dissatisfied teachers are less likely to do their best work in the classroom Evans, (2001). The findings obtained in this confirmed that of Evans, because teachers were not satisfied with their job, they felt reluctant, bored and unhappy to go to school, left alone for them to even teach. Quality teaching of these Teachers was questionable. They taught their students without any motivational interest. The poor situation either made teachers to be sacked by their superiors or to quit teaching voluntarily, consequently resulting in high teacher turnover. Nevertheless teachers who could not perform had threats of being sacked. Thus, although teacher turnover provides some positive outcomes Macdonald, (1999), such as the loss of incompetent teachers it can also contribute to distributional inequity of the quality of education service in some critical subjects like mathematics and science and regions (e. g., urban or rural areas). Furthermore, teacher turnover produces costs and disruption associated with recruiting, hiring and induction efforts (Boe, 1997).

\section{Working environment as a factor of turnover intentions.}

According to Mobbley (1982), extrinsic sources of satisfaction are situational and depend on the environment such as pay, promotion or job security: these are financial and other material rewards of a job. This aspect of job satisfaction is related to turnover intentions. The analysis of the data gathered suggested that there was a negative relationship between working environment and job satisfaction, meaning, teachers' working environment was dependent on turnover intentions. The results obtained in this study strongly agreed with Hanushek, et al. (1999) who stated that overall, higher salary is associated with lower teacher attrition, but the effect of salary is small and varies within characteristics of subpopulations. For example, using several logistic regression equation models, Hanushek, et al. (1999) found that salary increases reduced the likelihood that teachers in Texas would leave their district, yet teacher mobility was much more strongly related to characteristics of the students than to salary. The main finding was that, teachers who were part of the study were not satisfied with their job as a result of the unfavorable working environment they found themselves in. The poor nature of the working environment and absence of motivation such as recognition, financial incentives and equity made teachers had intentions of quitting the teaching career.

\section{Teacher characteristics associated with turnover intentions.}

The result shows that male teachers and female teachers have significant difference in turnover intentions. Thus, the data gathered supported the hypothesis that; males have more intentions of leaving the teaching field than females. The difference in turnover intentions can partly be attributed to the high level of commitment demonstrated by women in their organization.

The fifth hypothesis which stated that teachers who have spent less than five years in the teaching profession were less likely to leave the profession in comparison to teachers who have spent more than five years was not supported by the data gathered. The findings obtained rather confirmed that teachers who had spent more than five years in the profession had intention of quitting the career; unfortunately these teachers were those who were of age 40-44 years. This contradiction in the findings can be attributed to cultural variations as well as individual differences. It can also be attributed to boredom, i. e. these teachers have been performing the same task for a longer time. This is a determinant of job satisfaction which can lead to higher intention of quitting the teaching profession. The growing demand for teachers is not simply caused by large increases in student enrollments and in teacher retirements, class size reduction, 
and insufficient production college graduates from teacher education programs another key source of this challenge lies in the high rate of teacher turnover (Grissmer, et al., 1997)

\section{Summary and Conclusion}

The study investigated the relationship between teachers' job satisfaction and turnover intentions. The hypothesis which stated' that; there will be a positive relationship between working environment and job satisfaction was not supported by the data gathered. Alternatively, the analysis suggested that there was a negative relationship between working environment and job satisfaction, meaning, teachers considered their job satisfactory as dependent variable on working environment. The main finding was that, teachers were not satisfied with their job as a result of the unfavorable working environment they found themselves in. The data supported the hypothesis which stated that job satisfaction will have a significant negative correlation on turnover intentions. The results showed that, teachers who were satisfied with their profession did not have the intention of quitting but those who were not satisfied had the intention of quitting the teaching job. The hypothesis which stated that working environment will be inversely related to turnover intention was not supported by the data gathered. Alternatively, the decision was that only when teachers were not satisfied with their working environment to some extent before thoughts of quitting the teaching profession crossed their minds. Furthermore, teachers will endure their poor working environment only to some level and then think of leaving the profession entirely. An independent t-test was conducted on the data gathered using Statistical Package for the Social Sciences (SPSS) software. The data gathered supported the hypothesis that; males have greater intentions of leaving the teaching field than females. The hypothesis which stated that teachers who have been in the teaching profession between $1-5$ years will have higher intentions of leaving the teaching profession than those who have spent 5 years and above was not supported by the data gathered. It is clear from the study that job satisfaction and turnover intentions are negatively correlated and therefore paramount to pay close attention to the study of job satisfaction among the teachers to sustain effective teaching and learning in schools.

\section{Recommendations}

It was found in the study that teachers who have been in the teaching profession for a relatively longer time had higher intentions of quitting; hence it is recommended that incentive packages should be given to teachers who have been in the profession for a relatively longer time as a motivating factor to ensure retention. The duration for the research should be extended to ensure effective, efficient and extensive work. It is therefore paramount to pay close attention to the study of job satisfaction among teachers to sustain effective teaching and learning in schools.

\section{References}

[1.] Baker, D., \& Smith, T. (1997). Teacher turnover and teacher quality: Refocusing the Teachers College Record, 99(1), 29-35.

[2.] Becker, G. S. (1993). Human capital: A theoretical and empirical analysis with special Reference to education (3rd ed. ). Chicago: University of Chicago Press.

[3.] Brewer, D. (1996). Career paths and quit decisions: Evidence from teaching. Journal of

[4.] Darling-Hammond, L. (1999). Solving the dilemmas of teacher supply, demand, and standards: How we can ensure a competent, caring, and qualified teacher for every child. New York, NY: National Commission on Teaching \& America's Future.

[5.] Darling-Hammond, L. (2000). Teacher quality and student achievement: A review of state policy evidence. Education Policy Analysis Archives, 8(1).

[6.] Ehrenberg, R. G., \& Smith, R. S. (2003). Modern labor economics: Theory and public policy ( $8^{\text {th }}$. ed. ). New York, NY : Addison Wesley Longman, Inc. 
South American Journal of Academic Research

Special Edition May 2016

[7.] Evans, L. (2001 ). Delving deeper into morale, job satisfaction and motivation among education professionals: Re-examining' the leadership dimension. Educational Management Administration, 29, 291 306.

[8.] Grissmer, D. W., \& Kirby, S. N. (1997). Teacher turnover' and teacher quality. Teachers College Record, 99(1), 45-56.

[9.] Hanushek, E. A., Kain, 1. F., \& Rivkin, S. G. (1999). Do higher salaries buy better teachers? (Working Paper No. 7082).Cambridge, M A: National Bureau of Economic Research.

[10.] Herzberg, F. (1968). Work and the nature of man. London: Staple Press.

[11.] Ingersoll, R. M. (2001 ). Teacher turnover, teacher shortages, and the organization of schools

[12.] Ingersoll, R. M. (2003a). ls there really a teacher shortage? Seattle, W A: Center for the (No.

Document R-01 -1 ). Seattle, W A: University of Washington, Center for the Study of Teaching and Policy.

Study of Teaching and Policy.

[13.] Judge, T. A., Bono, J. E., \& Locke, E. A. (2000). Personality and job satisfaction: The mediating role of job characteristics. Journal of Applied Psychology, 85(2), 237-249.

[14.] Kirby, S. N., \& Grissmer, D. W. (1993). Teacher attrition: Theory, evidence, and suggested policy options. Santa Monica, CA: RAND

[15.] Macdonald, D. (1999). Teacher attrition: a review of literature. Teaching and Teacher Education, 15(8), 835-848

[16.] Niehoff, B. P. \& Moorman, R. H. (1993). Justice as a mediator of the relationship between methods of monitoring and organizational citizenship behavior. Academy of Management Journal, 36, 527-556.

[17.] Vandenberg, R. 1., \& Nelson, J. B. (1999). Disaggregating the motives underlying turnover intentions: When do intentions predict turnover behavior? Human Relations, 52(10), 1313-1336. 